\title{
Örme Kumaş Gözenekliliği ile Hava Geçirgenliği Arasındaki İlişkinin İncelenmesi
}

\author{
Abdurrahman TELLI $\dot{I}^{* 1}$ \\ ${ }^{1}$ Çukurova Üniversitesi, Mühendislik Fakültesi, Tekstil Mühendisliği Bölümü, Adana
}

Geliş tarihi: 26.08 .2020

Kabul tarihi: 31.03 .2021

$\ddot{\mathbf{O} z}$

Bu çalışmada farklı yapı ve özellikte on iki adet 1x1 rib örme kumaş kullanılmıştır. Örme kumaşların hava geçirgenlikleri ölçülmüş ve mikroskop altında görüntüleri alınmıştır. Görsellerin MATLAB paket programında görüntü işleme teknikleriyle görüntü doku parametreleri analiz edilmiştir. Kumaş gözenekliliği ile ilgili sekiz farklı görüntü doku parametresi ve hava geçirgenliği arasındaki ilişki korelasyon analizi ile istatistiki olarak incelenmiştir. Aynı hammaddeden üretilmiş kumaşlarda kumaş gözenekliliği parametreleri ile hava geçirgenliği arasında güçlü bir ilişki bulunmuştur. Ancak farklı hammaddeler kullanıldığında bu güçlü ilişkinin azaldığı gözlenmiştir. Örme kumaşların hava geçirgenliği üzerinde iplik ve kumaş gözenekliliğine ek olarak lif özellikleri ve karışım oranının da etkileri tespit edilmiştir.

Anahtar Kelimeler: Rib örme kumaş, Hava geçirgenliği, Görüntü işleme, Görüntü doku parametresi

\section{Investigation of the Relationship Between Porosity of Knitted Fabrics and Air Permeability}

\begin{abstract}
In this study, twelve $1 \times 1$ rib knitted fabrics containing different structure and features were used. Air permeability of knitted fabrics was measured and their images were taken under a microscope. Textural properties of images were analyzed with image processing techniques in MATLAB package program. The relationship between air permeability and eight different textural parameters of images related to fabric porosity were analyzed statistically with correlation analysis. A strong relationship was found between fabric porosity parameters and air permeability in fabrics produced from the same raw material. However, it was observed that this strong relationship decreased when different raw materials were preferred. The effects of fiber properties and blending ratio were determined on the air permeability of knitted fabrics in addition to yarn and fabric porosity.
\end{abstract}

Keywords: Rib knitted fabric, Air permeability, Image processing, Textural parameters of images

*Sorumlu yazar (Corresponding author): Abdurrahman TELLİ, atelli@cu.edu.tr 


\section{GíRiş}

Hava geçirgenliği tekstil mamullerinin en önemli fiziksel özelliklerinden birisidir. Kullanım yerine göre farklı hava geçirgenliği değerleri istenebilmektedir. Hava geçirgenliği lif, iplik, kumaş ve bitim işlemleri gibi çok sayıda parametreden etkilenmektedir. Tüm bu parametreler birbirleriyle ilişkilidir. Temel olarak hava geçirgenliğinin kumaşın toplam gözenekliliği ile ilgili olduğu söylenebilir. Toplam gözenekliliği etkileyen tüm yapisal parametreler hava geçirgenliğini de dolaylı olarak etkilemektedir. Toplam gözeneklilik lif içi gözeneklilik, iplik içerisinde lifler arasında kalan boşluklar ve kumaş içerisinde iplikler arasında kalan boşluklardan oluşmaktadır. Ancak hava akımının farklı büyüklükteki gözeneklerden öncelikle büyük gözeneği tercih etmesinden dolayı kumaş içerisindeki iplikler arasında kalan makro boşluklar hava geçirgenliği üzerinde daha fazla etkili olmaktadır. Kumaş sıklığındaki artış ile bahsedilen diğer gözenek boyutlarının da etkisi ortaya çıkmaktadır. Önceki çalışmalarda hava geçirgenliği, kumaş gözenekliliği ile ilgili parametreler kullanılarak tahminlenmeye çalışılmıştır $[1,2]$.

Önemli sayıda çalışmada 1şık geçirgenliği, kumaş gözenekliliği ve hava geçirgenliği arasındaki ilişki incelenmiştir. Militky ve arkadaşları (1999) 1 şı geçirgenliği vasıtasıyla dokuma kumaş gözenekliliğini açıklamaya çalışmışlardır. Işık geçirgenliğini görüntü analizi yardımıyla incelemişlerdir. Işık geçen alanın toplam alan içerisindeki oranını hesaplamışlardır. Elde ettikleri sonuçları hava geçirgenliği test sonuçları ile karşılaştırmışlardır [3]. Çay ve arkadaşları (2007) sabit bir 1şık kaynağ üzerine yerleştirilen pamuklu dokuma kumaşlardan aldıkları mikroskop görüntülerini analiz etmişlerdir. Hava geçirgenliği, su geçirgenliği, boyama vb. birçok özelliğin kumaşın gözenekliliği ile yakından ilgili olduğu belirtilen çalışmada, gözenekliliğin hesaplanmasinda temel problemin tekstil yapılarının deformasyonu, pürüzlülüğü ve düzensiz gözenek boyutu dağılımı olduğunu vurgulamışlardır. Kumaşın şekil özelliklerine bağlı olan teorik hesaplamaların hava geçirgenliğinin pratik olarak tahmininde verimli olmadığını söylemişlerdir. Hava geçirgenliği ile alınan görüntülerdeki parlaklık arasında doğrusal bir ilişki bulunduğunu belirlemişlerdir. Önerilen yöntemin sıkı yapıda olan kumaşlarda daha güvenilir olacağını da yorumlarına eklemiş̧lerdir [4]. Iş̧1k geçirgenliği ile hava geçirgenliği arasındaki ilişkinin incelendiği Haleem ve arkadaşları (2014) tarafindan yapılan diğer bir çalışmada ise görüntü analizine ek olarak bir 1 şı sensörü ile kumaştan geçen 1şığın yoğunluğu ölçülmeye çalışılmıştır. Her iki yöntemde de 1 şık ve hava geçirgenliği arasında güçlü korelasyon tespit edilmiştir [5]. Nazir ve arkadaşları (2017) tarafından yapılan çalışmada ise, hava geçirgenliğini belirlemek için geleneksel yöntemlerdeki kumaş içerisinden geçirilen havadan farklı olarak kumaş yapısına zarar vermeden 1şık geçirgenliğinin kullanılabileceği belirtilmiştir. Farklı yapı ve bileşimdeki kumaşlar ile daha fazla çalışma yapılması gerektiği de çalışmada vurgulanmıştır [6].

Mavruz ve Ogulata (2009) pamuklu örme süprem, ribana ve interlok örme kumaşların hava geçirgenliklerinin; iplik numarası, kalınlık, ilmek sıklığı ve ilmek iplik uzunluğundan oluşan regresyon denklemleriyle tahmin edilebileceğini belirtmişlerdir [7]. Zupin ve arkadaşları (2011) tek katlı pamuklu dokuma kumaşların hava geçirgenliği üzerinde en önemli etkiye sahip az sayıda parametreyi tanımlamaya çalışmışlardır. Gözeneklerin hidrolik çapı, makro gözeneklerin sayısı ve dokuma kumaşın toplam gözenekliliğini içeren modelde hava geçirgenliği sonuçları ile yüksek oranda ilişki bulmuşlardır [8].

Turan ve Okur (2012) hava geçirgenliğinin hesaplanmasını kumaş gözenekliliğinin hesaplanmasına dayandırdıkları çalışmalarında, pamuklu dokuma kumaşların iplikler arası gözenekliliği, gözenek boyutu ve gözenek boyutu dağılımlarını iki boyutlu (2B) ve üç boyutlu (3B) geometrik gözenek modelleri ve görüntü analiz yöntemi kullanarak hesaplamışlardır. Görüntü analiz yönteminde, görüntüler mikroskopta kumaş numunelerine alttan 1 şı vererek yakalanmıştır. Gözenekli bölgeler parlak, iplik olan bölgeler 1 şık 
geçirmedikleri için karanlık görülmüştür. $2 \mathrm{~B}$ ve $3 \mathrm{~B}$ geometrik modeller ile karşılaştırıldığında, görüntü analizinin gözenek boyutu ve dağılımı konusunda daha objektif sonuçlar verdiği belirtilmiştir [9]. Mezarcıöz ve arkadaşları (2013) örme kumaşların hava geçirgenliğinin tahmini için görüntü analiz sisteminde hesaplanan gözeneklilik ile teorik model ile hesaplanan gözeneklilik değerlerini kullanmışlardır. Farklı yap1 ve özellikteki \%100 pamuk düz örgü kumaşların kullanıldı $\breve{g}_{1}$ çalışmada, teorik model ile hava geçirgenliği arasında görüntü işlemeye göre daha yüksek korelasyon sonuçları elde edilmiştir. Çalışmada görüntü işleme tekniğinin eksik yönleri vurgulanmıştır [10]. Gültekin ve arkadaşları (2020) dokusuz yüzey kumaşların gözeneklilik ve hava geçirgenliği özelliklerini doku özelliklerinden tahmin etmek için yapay zekâ algoritması geliştirmeye çalışmışlardır. Sonuçlar hava geçirgenliği ve gözeneklilik arasında çok yakın bir ilişki olduğunu göstermiştir. Yapay sinir ağı ile düşük ağırlıktaki nonwoven malzemelerin hava geçirgenliği ve gözenek özelliklerinin doku görüntülerinden yüksek doğrulukta tahmin edilebileceği belirlenmiştir [11].
Bu çalışmada daha önceki çalıșmalardan farklı olarak, mikroskop altında alınan örme kumaş görüntülerinin MATLAB yazılımındaki sekiz farklı doku parametresindeki sonuçları belirlenmiştir. Elde edilen sonuçlar ile deneysel olarak elde edilen hava geçirgenliği değerleri arasındaki ilişki korelasyon analizi yardımıyla incelenmiştir.

\section{MATERYAL VE METOT}

Çalışmada beş farklı iplik numarası (Ne13, Ne16, Ne20, Ne28, Ne30), üç farklı hammadde (pamuk, pamuk/viskon, polyester/viskon) ve iki farklı iplik besleme ( 2 ve 3 adet iplik) ile 12 fine incelikte Shima Seiki SFF152 marka örme makinesinde farklı gramajlarda üretilmiş 12 adet $1 \times 1$ rib örme kumaş kullanılmıştır. Kumaşlara ait özellikler Çizelge 1'de verilmektedir. Kumaşların hava geçirgenliği testleri "Prowhite EP08M Hava Geçirgenliği Test Cihazı" kullanılarak TS 391 EN ISO 9237 standardına göre gerçekleştirilmiştir. Ölçümler, $100 \mathrm{~Pa}$ basınç ve $20 \mathrm{~cm}^{2}$ 'lik alanda $\mathrm{mm} / \mathrm{s}$ cinsinden yapılmıştır. 10 tekrarlı olarak gerçekleştirilmiştir.

Çizelge 1. Kullanılan örme kumaşların özellikleri

\begin{tabular}{|c|c|c|c|c|c|c|c|}
\hline Tip & $\begin{array}{c}\text { İplik } \\
\text { Besleme } \\
\text { (adet) }\end{array}$ & $\begin{array}{c}\text { Çubuk } \\
\text { Sıklığı } \\
\text { (çubuk / } \\
\text { cm) }\end{array}$ & $\begin{array}{c}\text { Sira } \\
\text { Sıklığı } \\
\text { (ilmek / } \\
\text { cm) }\end{array}$ & $\begin{array}{l}\text { İlmek İplik } \\
\text { Uzunluğu } \\
\text { (cm / ilmek) }\end{array}$ & $\begin{array}{c}\text { Kumaş } \\
\text { Gramajı } \\
\left(\mathbf{g} / \mathbf{m}^{2}\right)\end{array}$ & $\begin{array}{c}\text { İplik Karışım } \\
\text { Oranı } \\
(\%)\end{array}$ & $\begin{array}{c}\text { İplik } \\
\text { Numarası } \\
\text { (Ne) }\end{array}$ \\
\hline 01 & 2 & 4,4 & 11 & 1,43 & 511 & \multirow{2}{*}{ \%100 Pamuk } & \multirow{2}{*}{$\mathrm{Ne} 16$} \\
\hline 02 & 3 & 5,8 & 11 & 1,49 & 1052 & & \\
\hline 03 & 2 & 4,4 & 9,5 & 1,46 & 360 & \multirow{2}{*}{ \% 100 Pamuk } & \multirow{2}{*}{$\mathrm{Ne} 20$} \\
\hline 04 & 3 & 5,1 & 10 & 1,53 & 693 & & \\
\hline 05 & 2 & 4,4 & 12 & 1,94 & 404 & \multirow{2}{*}{$\% 100$ Pamuk } & \multirow{2}{*}{$\mathrm{Ne} 30$} \\
\hline 06 & 3 & 5,8 & 10,5 & 1,84 & 663 & & \\
\hline 07 & 2 & 4,7 & 10,5 & 1,41 & 631 & \multirow{2}{*}{$\begin{array}{l}\% 50 \text { Pamuk / } \\
\% 50 \text { Viskon }\end{array}$} & \multirow{2}{*}{ Ne 13} \\
\hline 08 & 3 & 5,8 & 11 & 1,51 & 1314 & & \\
\hline 09 & 2 & 4,4 & 9,5 & 1,49 & 367 & \multirow{2}{*}{$\begin{array}{l}\text { \%50 Pamuk / } \\
\% 50 \text { Viskon }\end{array}$} & \multirow{2}{*}{$\mathrm{Ne} 20$} \\
\hline 10 & 3 & 4,7 & 11 & 1,43 & 656 & & \\
\hline 11 & 2 & 3,6 & 8 & 1,43 & 174 & \multirow{2}{*}{$\begin{array}{l}\% 50 \text { Viskon / } \\
\% 50 \text { Polyester }\end{array}$} & \multirow{2}{*}{$\mathrm{Ne} 28$} \\
\hline 12 & 3 & 3,7 & 9 & 1,44 & 303 & & \\
\hline
\end{tabular}


Hava geçirgenliği testinden önce kumaşların 10x (10 kat) büyütme oranında Novel NSZ 808 marka stereomikroskop kullanılarak RGB formatında görüntüleri 1880x2590 piksel olarak alınmıştır. Her kumaştan 10 görüntü alınmıştır. Kullanılan mikroskop görüntülerinde, alt bölümden verilen sabit 1şık kaynağ 1 sayesinde kumaş yüzeyindeki gözeneklilikler ortaya çıkmaktadır. Farklı gözenek boyut ve dağılımına sahip örme kumaşların farklı yap1 ve özellikleri nedeniyle farklı oranlarda 1 şı ̆̆ geçirecekleri düşüncesinden hareket edilmiştir. Tüm testler, 24 saat süreyle TS EN ISO 139`a göre kondüsyonlanıp standart atmosfer koşullarında $\left(20^{\circ} \mathrm{C} \pm 2\right.$ sıcaklık, $\% 65 \pm 4$ bağıl nem) yapılmıştır.

Alınan örme kumaş görselleri üzerinde yapılan görüntü analiz çalışmaları MATLAB R2018a paket programında gerçekleştirilmiştir. İlk olarak MATLAB yazılımına üç boyutlu resim (RGB) yüklenmektedir. Sistemde " 1880 X2590X3 uint 8" formatında üç boyutlu matrise sahip olan resim, 0 ile 256 arasında grinin farklı tonlarını ifade eden "1880X2590 uint8" şeklinde iki boyutlu matrislere dönüştürülmüştür. Daha sonra matrisler üzerinde doku analizi yapabilmek için 0-1 arasında değer alacak şekilde " $1880 \times 2590$ double" hale getirilmektedir [12]. Bir sonraki işlem olarak elde edilen görüntü matrislerindeki gürültüyü azaltmak için medfilt2 (2D median filtering) temel filtreleme tekniği uygulanmıştır [13-14]. Filtre uygulanmış görüntülerde histogram eşitleme tekniği kullanılarak görüntü bölütleme için en uygun eşik değeri hesaplanmıştır. Bölütlemede, eşikli siyah ve beyaz piksellerin sınıf içi varyansını en aza indirmek için eşik değerini seçen Otsu'nun global eşikleme algoritması kullanılmıştır. Bu algoritma, tek bir eșik değeri kullanarak görüntü histogramını göstererek görüntüyü bölütleyen eşikleme yöntemidir [14-18].

Elde edilen görüntü matrislerinde kumaş gözenekliliği hakkında bilgi sahibi olabilmek için görsellerin yedi farklı doku parametresi incelenmiştir. Bunlar karşıtlık (contrast), korelasyon (correlation), enerji (energy), homojenlik (homogeneity), matris elemanlarının ortalaması (mean2), matris elemanlarının standart sapması (std2) ve entropisi (entropy) şeklindedir.
Karşıtlık, korelasyon, enerji ve homojenlik, gri düzey eş oluşum matrisinden (GLCM) türetilen görüntünün istatistiksel özellikleridir. Kontrast, GLCM'deki bölgesel varyasyonları ölçmektedir. Korelasyon, belirtilen piksel çiftlerinin birleşik olasılığını test etmektedir. Enerji, GLCM'deki kare öğelerin toplamını vermektedir. Homojenlik, GLCM'deki elemanların dağılımının GLCM diyagonaline yakınlığını ölçmektedir. Matris elemanlarının ortalaması, dizideki tüm değerlerin ortalamasıdır. Matris elemanlarının standart sapmas1, piksel yoğunluğu değerlerinin standart sapmasıdır. Entropi, normalleştirilmiş histogram sayılarıyla ilgilidir. Ayrıca "Image Region Analyzer" kullanılarak görüntüler bölgesel olarak analiz edilmiştir [13-15,19]. Görüntü matrislerindeki kumaş yüzeyin kapladığı alan dışındaki "toplam alan" hesaplanmıştır. Daha sonra hesaplanan bu sekiz parametrenin hava geçirgenliği test sonuçları ile arasındaki ilişki Pearson bağıntı (korelasyon) analizi kullanılarak istatistiki olarak incelenmiştir. Bağıntı katsayısındaki önem seviyeleri Çizelge 2'de gösterilmektedir [20].

Çizelge 2. Bağıntı katsayısındaki önem seviyeleri

\begin{tabular}{|c|l|}
\hline Bağıntı katsayısı (r) & Anlamı \\
\hline $0-0,25$ & $\begin{array}{l}\text { Hiç ilişki yok ya da } \\
\text { çok zayıf }\end{array}$ \\
\hline $0,25-0,50$ & Zayıf derecede ilişki \\
\hline $0,50-0,75$ & Orta derecede ilişki \\
\hline $0,75-1,00$ & Güçlü derecede ilişki \\
\hline
\end{tabular}

\section{BULGULAR VE TARTIŞMA}

Şekil 1'de örnek olması açısından "12" nolu kumaştan alınan ilk görselin görüntü işleme öncesi mikroskobik görüntüsü, görüntü işleme adımları ve sonrasındaki elde edilen görüntüleri sunulmaktadır. Görüntü işleme adımları sonrasında elde edilen görüntülerde, RGB formatındaki üç boyutlu matrise sahip resimlerin 0-1 arasında değer alacak şekilde gri düzey eş oluşum matrislerinin elde edilip filtreleme tekniğiyle görüntüdeki gürültülerin azaltılması ile yüzey gözenekliklerinin daha net bir şekilde ortaya çıktığg 1 görülmektedir. 


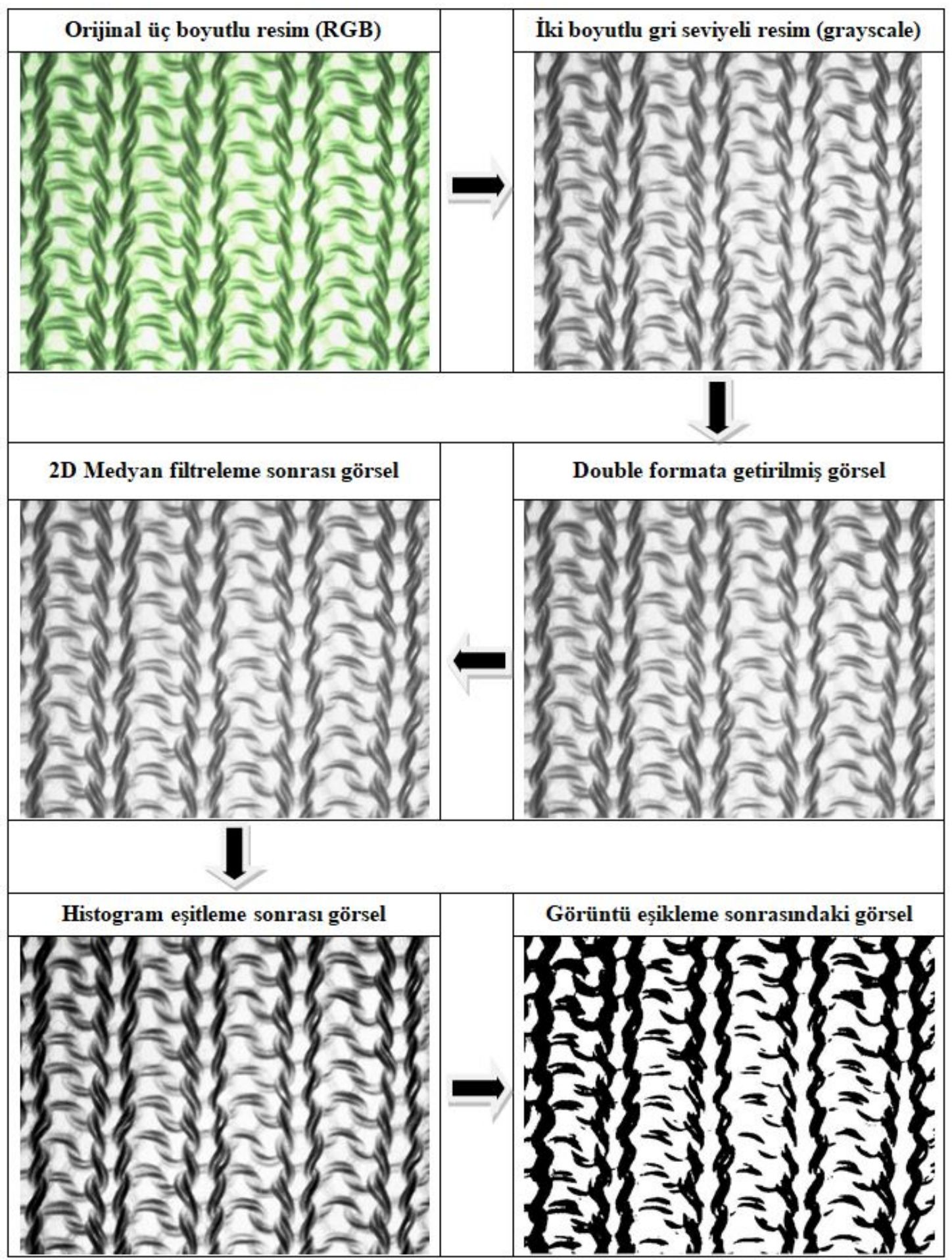

Şekil 1. Görüntü işleme öncesi, adımları ve sonrası kumaş görselleri 
Çizelge 3'de kumaşların hava geçirgenliklerinin $\mathrm{mm} / \mathrm{s}$ cinsinden ortalama test sonuçları ve görüntü analiz sonrasındaki kumaş görüntülerine ait yedi doku parametresi ve görüntü matrislerinde kumaş yüzeyin kapladığı alan dişındaki "toplam alan" hesabından oluşan sekiz parametrenin ortalama değerleri verilmektedir. Çizelge 3'deki hava geçirgenliği sonuçları, Çizelge 1'de verilen örme kumaş özellikleri ile birlikte düşünüldüğünde, aynı iplik kullanılan kumaşlarda $(1-2,3-4,5-6,7-8$, 9$10,11-12$ ) bir iğneye beslenen iplik adedinin 2 'den 3'e çıkarıldığında hava geçirgenliği değerlerinin azaldığı görülmektedir. Aynı iplik besleme adetlerinde, üç adet beslemelerde (2-4-6, 8-10-12) iplik numarası inceldikçe hava geçirgenliğinde artış gözlenmiştir. İki adet beslemelerde ise "7-911" nolu kumaşlar arasında artış görülmüştür. Ancak " 01 " nolu kumaşa göre " 03 " ve " 05 " nolu kumaşlarda daha yükssek hava geçirgenliği görülürken, "03" ve "05” nolu kumaşlar arasında önemli bir fark tespit edilememiştir. Sonuçlar kumaş içerisindeki iplikler arasında kalan makro boşlukların hava geçirgenliği üzerinde önemli seviyede etkili olduğunu göstermektedir. Sadece "05" nolu kumaşta görülen farklı durum, bu kumaşın Çizelge 1'deki en yüksek ilmek iplik uzunluğuna sahip olmasından kaynaklanmaktadır. Elde edilen bulgular daha önceki çalışmalarda belirtilen bilgiler ile uyum göstermektedir [1-2,8, 10]. Çizelge 3 'deki en düşük hava geçirgenliğinin " 08 " nolu kumaşta ölçüldüğü görülmektedir. En yüksek hava geçirgenliği ise "11" nolu kumaşta bulunmuştur. Çizelge 1'de bu iki kumaşın en yüksek ve en düşük gramaj değerlerine sahip olduğu gözlenmektedir.

Çizelge 3'de "toplam alan" 953709 piksel olarak en düşük "02" nolu kumaşta ölçülmüştür. Daha sonra en düşük değere 1051260 piksel ile " 08 " nolu kumaş sahiptir. Bu durum toplam alan hesabının doku özelliklerindeki karşılığı matris elemanlarının ortalaması (mean2) değerlerinde daha kolay takip edilebilmektedir. Kumaş yüzeyin kapladığı alan dışındaki "toplam alan”, bir başka ifade ile görüntüdeki beyaz piksellerin, görüntüdeki toplam piksel sayısına $(1880 * 2590)$ bölümünü ifade eden "mean2" değerlerinde de en düşük değer " 02 " nolu kumaşta, daha sonra " 08 " nolu kumaşta ölçülmüştür. " 02 ” nolu kumaşta beyaz piksellerin yüzdesi 19,59 ve " 08 " nolu kumaşta \%21,59 olduğu görülmektedir (Çizelge 3).

Çizelge 3. Hava geçirgenliği ve sekiz farklı doku parametresinin ortalama test sonuçları

\begin{tabular}{|c|c|c|c|c|c|c|c|c|c|}
\hline 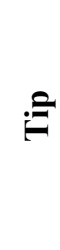 & 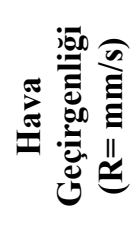 & 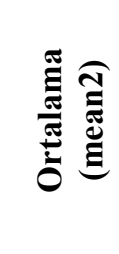 & 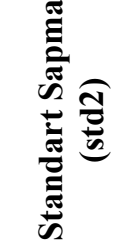 & 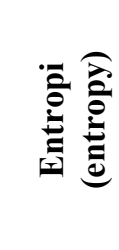 & 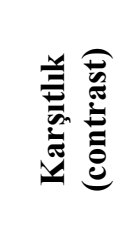 & 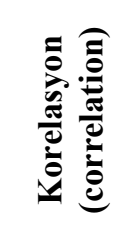 & 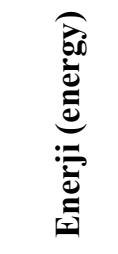 & 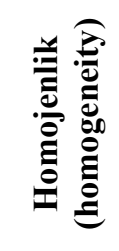 & 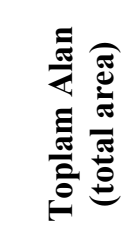 \\
\hline 01 & 879,2 & 0,3942 & 0,4870 & 0,9628 & 0,0123 & 0,9741 & 0,5134 & 0,9939 & 1919341 \\
\hline 02 & 156,9 & 0,1959 & 0,3968 & 0,7135 & 0,0106 & 0,9663 & 0,6745 & 0,9947 & 953709 \\
\hline 03 & 1047,7 & 0,5538 & 0,4965 & 0,9900 & 0,0116 & 0,9765 & 0,4955 & 0,9942 & 2696382 \\
\hline 04 & 310,6 & 0,2624 & 0,4388 & 0,8274 & 0,0093 & 0,9757 & 0,6052 & 0,9953 & 1277533 \\
\hline 05 & 1025,1 & 0,5793 & 0,4921 & 0,9772 & 0,0123 & 0,9746 & 0,5036 & 0,9938 & 2826691 \\
\hline 06 & 414,6 & 0,3278 & 0,4688 & 0,9111 & 0,0113 & 0,9744 & 0,5491 & 0,9944 & 1596169 \\
\hline 07 & 488,3 & 0,3998 & 0,4892 & 0,9689 & 0,0102 & 0,9787 & 0,5113 & 0,9949 & 1946714 \\
\hline 08 & 103,2 & 0,2159 & 0,4109 & 0,7513 & 0,0125 & 0,9630 & 0,6497 & 0,9938 & 1051260 \\
\hline 09 & 1150,7 & 0,6171 & 0,4847 & 0,9561 & 0,0133 & 0,9716 & 0,5168 & 0,9933 & 3004753 \\
\hline 10 & 509,8 & 0,3851 & 0,4864 & 0,9610 & 0,0117 & 0,9753 & 0,5152 & 0,9942 & 1874977 \\
\hline 11 & 2444,8 & 0,6058 & 0,4866 & 0,9617 & 0,0132 & 0,9721 & 0,5132 & 0,9934 & 2949626 \\
\hline 12 & 1961,9 & 0,6611 & 0,4709 & 0,9171 & 0,0125 & 0,9718 & 0,5437 & 0,9938 & 3218802 \\
\hline
\end{tabular}


Diğer dokusal parametrelerde ise benzer şekilde "02" nolu kumaş en düşük standart sapma, entropi ve karşıtlık değerleri ile en yüksek enerji değerlerine sahip olmuştur. Bütünü görebilmek amacıyla, tüm kumaşlardaki hava geçirgenliği ile görüntü doku parametreleri ve gramaj test sonuçları arasındaki ilişki Çizelge 4'de bağıntı analizi ile incelenmektedir

Sonuçlar incelendiğinde hava geçirgenliği ile matris elemanlarının ortalaması ve toplam alan arasında pozitif yönlü güçlü bir korelasyon olduğu görülmektedir $(\mathrm{r}=0,860)$. $\mathrm{Bu}$ iki değer arttıkça hava geçirgenliği de artmaktadır. Hava geçirgenliği ile gramaj değerleri arasında da negatif yönlü güçlü bir korelasyon bulunmuştur $(\mathrm{r}=-0,824)$. Diğer doku parametrelerinden karşıtlık $(\mathrm{r}=0,628)$, entropi $(\mathrm{r}=0,535)$ ve standart sapma $(\mathrm{r}=0,535)$ ile hava geçirgenliği arasında pozitif yönde orta düzeyde ilişki bulunurken, enerji ( $\mathrm{r}=$ $0,543)$ ve homojenlik $(\mathrm{r}=-0,638)$ ile arasinda negatif yönde orta düzeyde ilişki tespit edilmiştir. Korelasyon parametresi ile hava geçirgenliği arasında önemli düzeyde bir ilişki ise bulunamamıştır. Çizelge 5'de ise \%100 pamuk içeren ilk altı kumaşın hava geçirgenliği ile görüntü doku parametreleri ve gramaj test sonuçları arasındaki ilişki sunulmaktadır.

Çizelge 4. Tüm kumaşlardaki hava geçirgenliği ile görüntü doku parametreleri ve gramaj test sonuçları arasındaki ilișki

\begin{tabular}{|c|c|c|c|c|c|c|c|c|c|}
\hline Tip & 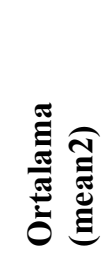 & 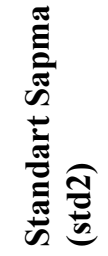 & 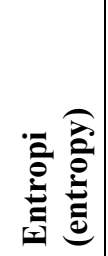 & 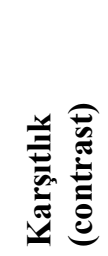 & 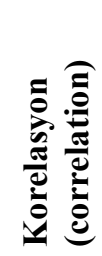 & 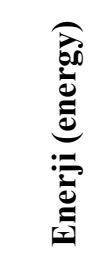 & 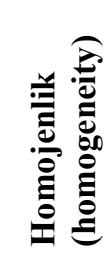 & 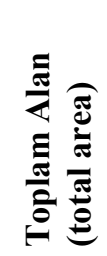 & 预 \\
\hline $\begin{array}{c}\text { Hava } \\
\text { Gecirgenliği }\end{array}$ & 0,860 & 0,535 & 0,535 & 0,628 & 0,146 & $-0,543$ & $-0,638$ & 0,860 & $-0,824$ \\
\hline
\end{tabular}

Çizelge 5. \%100 pamuk içeren ilk altı kumaşın hava geçirgenliği ile görüntü doku parametreleri ve gramaj test sonuçları arasındaki ilişki

\begin{tabular}{|c|c|c|c|c|c|c|c|c|c|}
\hline Tip & 胥 & 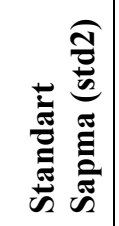 & 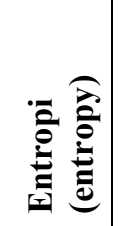 & 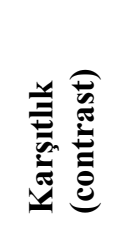 & 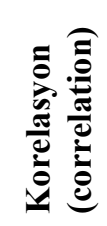 & 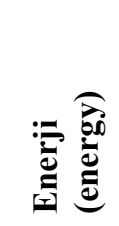 & 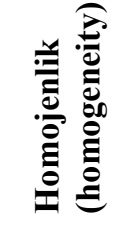 & 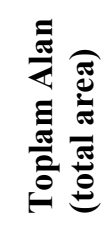 & 芯 \\
\hline $\begin{array}{c}\text { Hava } \\
\text { Geçirgenliği }\end{array}$ & 0,958 & 0,912 & 0,915 & 0,779 & 0,602 & $-0,923$ & $-0,803$ & 0,957 & $-0,926$ \\
\hline
\end{tabular}

Çizelge 5'deki sonuçlar incelendiğinde Çizelge 4'deki sonuçlara benzer şekilde hava geçirgenliği ile matris elemanlarının ortalaması ve toplam alan arasında pozitif yönlü güçlü bir korelasyon olduğu görülmektedir. Ancak \%100 pamuk içeren ilk altı kumaşın verilerinde bağıntı katsayısı değeri daha güçlüdür $(\mathrm{r}=0,958)$. Hava geçirgenliği ile gramaj değerleri arasında da
Çizelge 4'deki sonuçlara benzer şekilde negatif yönlü güçlü bir korelasyon bulunmuştur. Ancak burada da \%100 pamuk içeren ilk altı kumaşın verilerinde bağıntı katsayısı değeri daha güçlüdür $(r=-0,926)$. Diğer görüntü doku parametrelerinde de tüm numune seti yerine $\% 100$ pamuk içeren ilk altı kumaş değerleri kullanıldığında bağıntı katsayısı değerleri yükselmiştir. Karşıtlık 
$(\mathrm{r}=0,779)$, entropi $(\mathrm{r}=0,915)$ ve standart sapma $(\mathrm{r}=0,912)$ ile hava geçirgenliği arasındaki orta düzeyde ilişki, pozitif yönde güçlü seviyeye ulaşmıştır. Benzer şekilde enerji $(r=-0,923)$ ve homojenlik $(\mathrm{r}=-0,803)$ ile hava geçirgenliği arasındaki negatif yöndeki orta düzeyde ilişki de güçlü seviyeye ulaşmıştır. Çizelge 4'de korelasyon parametresi ile hava geçirgenliği arasında önemli düzeyde bir ilişki bulunamamışken, Çizelge 5'de pozitif yönde orta düzeyde bir ilişki tespit edilmiştir $(r=0,602)$.

Çizelge 4 ve 5'deki sonuçlar beraber değerlendirildiğinde, aynı hammaddeden üretilmiş kumaşlarda, görüntü analiz yardımıyla incelenen kumaş gözenekliliğini ifade eden doku parametreleri ile hava geçirgenliği arasında güçlü bir ilişki bulunurken, farklı hammaddeler devreye girdiğinde bu güçlü ilişkinin azaldı $\breve{g ̆}_{1}$ görülmektedir. Hava geçirgenliği ile arasında güçlü korelasyon bulunan yedi görüntü doku parametresi ikiye düşmektedir. Ayrıca kalan iki parametre ile hava geçirgenliği arasındaki bağıntı katsayısı değeri de düşmektedir. Çizelge 1'de kullanılan örme kumaşların özellikleri ve Çizelge 3'deki hava geçirgenliği değerleri birlikte incelendiğinde, lif cinsi ve oranlarındaki değişimin etkisi görülmektedir. Aynı iplik numarasının (Ne 20) ve iplik besleme adedinin (2) kullanıldığ 1 , yakın gramaj değerlerine sahip "03"nolu (360 g/m²) \%100 Pamuk kumaş ve “09"nolu (367 g/m²) \%50 Pamuk / \%50 Viskon kumaş arasında hava geçirgenliği değerleri önemli farklılık göstermiştir. Viskon içeren “09”nolu kumaşlarda daha yüksek hava geçirgenliği ölçülmüştür. Benzer şekilde, aynı iplik numarasının (Ne 20) ve iplik besleme adedinin (3) kullanıldı ğ " 04 " ve "10" nolu kumaşlarda; viskon içeren "10"nolu (656 g/m²) \%50 Pamuk/\%50 Viskon kumaş, “04”nolu (693 g/m²) \%100 Pamuk kumaşa göre bir miktar daha az gramaj değerine sahip olmakla birlikte önemli seviyede fazla hava geçirgenliği göstermiştir. Literatürde de viskon lif içeren iplik ve kumaşların, aynı yapı ve özellikteki pamuk içerenlere göre daha yüksek hava geçirgenliğine sahip olduğu bildirilmektedir [2122].
Ayrıca yakın gramaj değerlerine sahip "06"nolu $\left(663 \mathrm{~g} / \mathrm{m}^{2}\right)$, “07” nolu $\left(631 \mathrm{~g} / \mathrm{m}^{2}\right)$ ve “10" nolu $\left(656 \mathrm{~g} / \mathrm{m}^{2}\right)$ kumaşlarda, "06”nolu (414,6 mm/s) \%100 Pamuk kumaşa göre " 07 ” nolu (488,3 mm/s) ve "10" nolu (509,3 mm/s) \%50 Pamuk/\%50 Viskon içeren kumaşların daha yüksek hava geçirgenliğine sahip olduğu görülmektedir. Benzer şekilde yakın gramaj değerlerine sahip “03"nolu $\left(360 \mathrm{~g} / \mathrm{m}^{2}\right)$, “09" nolu $\left(367 \mathrm{~g} / \mathrm{m}^{2}\right)$ ve “12" nolu (303 g/m²) kumaşlarda, “03”nolu (1047,7 mm/s) \%100 Pamuk kumaşa göre "09" nolu $(1150,7 \mathrm{~mm} / \mathrm{s})$ \%50 Pamuk/\%50 Viskon içeren kumaşta daha yüksek hava geçirgenliği ölçülmüştür. Pamuk lifinin yer almadığ $\% 50$ Viskon/\%50 Polyester içeren "12" nolu kumaşta, 1961,9 mm/s ile tüm kumaşlar arasında ikinci en yüksek hava geçirgenliği değeri ölçülmüştür.

\section{SONUÇ}

$\mathrm{Bu}$ çalışmada farklı yapı ve özellikteki örme kumaşların mikroskop altındaki görüntülerinden, görüntü analiz teknikleriyle elde edilen kumaş gözenekliliğini ifade eden görüntü doku parametreleri ile hava geçirgenlikleri arasındaki ilişki incelenmiştir. Hava geçirgenliği ve kumaş gözenekliliği ile ilgili iki parametre arasında güçlü ilişki bulunmuştur. Ancak daha önceki çalışmalardan farklı olarak, 1şık geçirgenliği yardımıyla kumaş gözenekliliği ile ilgili görüntü doku parametreleri ile hava geçirgenliğinin örme kumaşlarda yüksek doğrulukta tahmin edilemeyeceği görülmüştür. Dokuma kumaşlara göre daha seyrek yapıda olan örme kumaşlarda, hava geçirgenliği üzerinde kumaş gözenekliliği başrol üstlenirken lif özellikleri ve karışım oranının da etkilerinin yadsınamayacağı tespit edilmiştir. Aynı hammaddeden kumaşlar için görüntü analiz çalışmaları hava geçirgenliğinin belirlenmesinde önemli bir seçenek olarak düşünülebilecekken, farklı hammaddelerde net sonuçlara ulaşılamayacağı açıktır. Çalışma örme kumaşlarda gözenekliliğin hava geçirgenliği için en önemli parametre olmakla birlikte tek başına yeterli olmadığını göstermektedir. İlerleyen çalışmalarda farklı lifler için oluşturulacak hava geçirgenliği katsayıları ile bu durum çözülerek daha kesin sonuçlara ulaşılabilecektir. 


\section{KAYNAKLAR}

1. Turan, R.B., Okur, A., 2008. Kumaşlarda Hava Geçirgenliği. Tekstil ve Mühendis, 15(72), 16-25.

2. Kırc1, T., Kanat, Z.E., Gülümser, T., Tarakçıŏlu, I., Taşkın, C., Çay, A., 2007. Tekstil Materyallerinde Gözenekliliğin Önemi, Tekstil \& Teknik, 23(271), 180-186.

3. Militky, J., Travnickova, M., Bajzik, V., 1999. Air Permeability and Light Transmission of Weaves. International Journal of Clothing Science and Technology, 11(2-3), 116-125.

4. Çay, A., Vassiliadis, S., Rangoussi, M. \& Tarakçığlu, I., 2007. On the Use of Image Processing Techniques for the Estimation of the Porosity of Textile Fabrics. International Journal of Materials and Textile Engineering, 1(2), 421-424.

5. Haleem, N., Ibrahim, S., Hussain, T., Jabbar, A., Malik, M.H., Malik, Z.A., 2014. Determining the Light Transmission of Woven Fabrics Through Different Measurement Methods and its Correlation with Air Permeability. Journal of Engineered Fibers and Fabrics, 9(4), 76-82.

6. Nazir, A., Hussain, T., Afzal, A., Faheem, S., Ibrahim, W., Bilal, M., 2017. Prediction and Correlation of Air Permeability and Light Transmission Properties of Woven Cotton Fabrics. Autex Research Journal, 17(1), 61-66.

7. Mavruz, S., Oğulata, R.T., 2009. Pamuklu Örme Kumaşlarda Hava Geçirgenliğinin İncelenmesi ve İstatistiksel Olarak Tahminlenmesi. Tekstil ve Konfeksiyon, 19(1), 29-38.

8. Zupin, Ž., Hladnik, A., Dimitrovski, K., 2012. Prediction of One-layer Woven Fabrics Air Permeability Using Porosity Parameters. Textile Research Journal, 82(2), 117-128.

9. Turan, R.B., Okur, A., 2012. Investigation of Pore Parameters of Woven Fabrics by Theoretical and Image Analysis Methods. Journal of the Textile Institute, 103(8), 875-884.

10. Mezarcioz, S., Bebekli, M., Ogulata, R.T., 2013. Prediction of the Air Permeability of Knitted Fabrics: Comparison of the Image
Analysis System and Theoretical Model, $8^{\text {th }}$ International Conference TEXSCI 2013, September 23-25, Liberec, Czech Republic.

11. Gültekin, E., Çelik, H. İ., Nohut, S., Elma, S.K., 2020. Predicting Air Permeability and Porosity of Nonwovens with Image Processing and Artificial Intelligence Methods. The Journal of the Textile Institute, DOI: 10.1080/00405000.2020.1727267

12. Telli, A., Özkan, İ., 2018. Görüntü İşleme Teknikleri ile Örme Kumaşlardaki Boncuklanma Direncinin Objektif Ölçümü. Tekstil ve Mühendis, 25(112), 313-318.

13. Telli A., 2019. Boncuklanma Görüntülerinin İşlenmesinde Farklı Filtrelerin Kullanımı, The International Conference of Materials and Engineering Technologies (TICMET'19), 1012 October 2019, 695-701.

14. Telli, A., 2020. The Relationship Between Subjective Pilling Evaluation Results and Detecting Pills and Textural Features in Knitted Fabrics. Fibers and Polymers, 21(8), 1841-1848.

15. Telli, A., 2019. An Image Processing Research Consistent with Standard Photographs to Determine Pilling Grade of Woven Fabrics. Tekstil ve Konfeksiyon, 29(3), 268-276.

16. Otsu, N., 1979. A Threshold Selection Method from Gray-level Histograms. IEEE Transactions on Systems, Man, and Cybernetics, 9(1), 62-66.

17. Perihanoğlu, G.M., 2015. Dijital Görüntü İşleme Teknikleri Kullanılarak Görüntülerden Detay Çıkarımı, İstanbul Teknik Üniversitesi Fen Bilimleri Enstitüsü Yüksek Lisans Tezi, İstanbul, 67.

18. MathWorks, Binarize 2-D Grayscale Image or 3-D Volume by Thresholding, https://uk. mathworks.com/help/images/ref/imbinarize.ht ml, Son Erişim: 10.01.2021.

19. MathWorks, Binarize 2-D Grayscale Image or 3-D Volume by Thresholding, https://uk. mathworks.com/help/images/ref/graycoprops.h tml, Son Erişim: 10.01.2021.

20. Özdemir, O., 2005. Medikal İstatistik. İstanbul Medikal Yayıncılık. İstanbul, 314.

21. Öner, E., Okur, A., 2015. Thermophysiological Comfort Properties of Selected Knitted Fabrics 
Örme Kumaş Gözenekliliği ile Hava Geçirgenliği Arasındaki Illişkinin İncelenmesi

and Design of T-shirts. The Journal of The Textile Institute, 106(12), 1403-1414.

22. Oner, E., 2019. Mechanical and Thermal Properties of Knitted Fabrics Produced from Various Fiber Types. Fibers and Polymers, 20(11), 2416-2425. 